\section{Surgical and Medical Treatment in Art}

ALAN EMERY, MARCIA EMERY

$\begin{array}{ll}\text { EXTENT P/H } & 138 \mathrm{p} \text {, hardback } \\ \text { PRICE/ISBN } & £ 45.00 \quad 1853156957 \\ \text { PUBLISHER } & \text { RSM (London), 2005 } \\ \text { REVIEWER } & \text { Brian Morgan } \\ \text { STAR RATING } & * * * *\end{array}$

I so enjoyed the relaxed reading and the paintings and artwork collected in this book that I can recommend it for any who are weary of the formal text of many of our medical books.

It is a companion to Medicine and Art published by the same authors in 2003. In this volume, Professor Emery and his wife Marcia have collected 66 works that are beautifully reproduced in colour plates and each is accompanied by a short essay giving a brief biography of the artist, an explanation of the topic and its relevance to treatment. They have particularly chosen to illustrate developments in treatment over many centuries from blood letting to liver transplants. The artwork is taken from 19th dynasty Egypt to contemporary painting so there is a wide spread of art styles.

As the authors say, it is a book to observe and ponder. I certainly was made to ponder on the rather strange representation by Ken Currie of the 'The Three Oncologists' from Dundee. Treatment problems and dilemmas are discussed. There are illustrations from the exhibitions A Picture of Health: Paintings and Drawings of Breast Cancer Care and Living with Leukaemia and I was sad to learn that the artist Susan Macfarlane had died after an accident. Some of the information and pictures might even come in handy for preparing lectures (with due acknowledgement of course!).

Choosing the works must have been difficult - there is an additional list of 154 works that are not illustrated - but the authors have helpfully provide the topic, artist and location of the paintings. Alan Emery is himself an artist and I hope that the Emerys will continue their research and writing. It might be worth them looking at Mark Gilbert's portrayal of head and neck surgery recently exhibited in the new Hunterian Museum.

\section{Controversies in Laparoscopic Surgery}

MICHEL GAGNE, AHMAD ASSALIA, MOSHE SCHEIN

\begin{tabular}{ll}
\hline EXTENT P/H & $444 \mathrm{p}$, hardback \\
PRICE/ISBN & $£ 77.00 \quad$ 3540229523 \\
PUBLISHER & Springer (Berlin), 2006 \\
REVIEWER & Joseph Varghese \\
STAR RATING & $* * * *$
\end{tabular}

The editors have prefaced this excellent book concisely. Although the advantages of laparoscopic surgery in certain fields of surgery do not need to be highlighted any further, the authors have critically analysed in detail the evidence available from various aspects and are to be credited for having carried out this vast exercise in a methodical manner.

This book has been written with a view to dissecting the available evidence for a number of topics in laparoscopic surgery. The majority of the contributors are from North America but the commentators are from other continents. One of them is not an advanced laparoscopic surgeon, thereby supporting their intention of providing a balanced opinion.

There are 32 chapters in this book, which has a particular emphasis on training, access and the physiological consequences of laparoscopic surgery. Topics such as laparoscopy in malignancy, trauma, hernia, reflux disease, morbid obesity, oesophagectomy, colorectal surgery and thyroid disease have been discussed in detail. These chapters have all been written with a critical eye towards the available evidence. At the end of each chapter there is a summary which is particularly useful as a quick reference.

It was most interesting to read the commentaries from world-renowned experts, some of whom touched on their experience in certain topics. Of note is that on gastrooesophageal reflux disease, in which it was extremely interesting to note that the gold-standard operation was based on very little evidence.

The presentation in this book makes it particularly easy to follow, with subject headings and questions for discussion. This book is an essential for the higher trainee laparoscopic surgeon and the trainer. Certain controversial topics like endoscopic, minimally invasive thyroid and parathyroid surgery will be useful as a reference for endocrine surgeons.

My overall score for this book is a 4 out of 5 and I will be using it as a reference in the future.

\section{Perforator Flaps: Anatomy, Technique and Clinical Applications}

PHILLIP BLONDEEL, STEVEN MORRIS, GEOFFREY HALLOCK, PETER NELIGAN

\begin{tabular}{ll}
\hline EXTENT P/H & $1000 \mathrm{p}$, hardback \\
PRICE/ISBN & $\$ 495.00 \quad 1576261786$ \\
PUBLISHER & Quality Medical Publishing (Missouri), 2005 \\
REVIEWER & Stephen Langton \\
STAR RATING & $* * * *$
\end{tabular}

This extensive and highly detailed work comprises two volumes and provides a comprehensive account of perforator flaps and their use in reconstructive surgery. Perforator flaps have gained popularity in recent years in many aspects of reconstruction and the initial chapter of the book provides a brief history of flap surgery, describing the 